\title{
Atmospheric oxygenation and volcanism
}

ARISING FROM F. Gaillard, B. Scaillet \& N. T. Arndt Nature 478, 229-232 (2011)

Around 2.5 billion years ago, Earth's atmosphere turned from anoxic to oxic in what is known as the Great Oxidation Event. Gaillard et al. ${ }^{1}$ suggest that this oxygenation was caused by the emergence of the continents and a shift in volcanism from predominantly submarine to primarily subaerial conditions. Because the ratio of volcanic $\mathrm{SO}_{2}$ to $\mathrm{H}_{2} \mathrm{~S}$ in their model increases with this shift, they argue that the atmosphere became more oxidized. But their model also predicts that outgassing of $\mathrm{CO}_{2}$ decreases at the lower pressure of continental volcanism, and that this should act against atmospheric oxygenation because $\mathrm{CO}_{2}$ is the substrate for the production of oxygen from photosynthesis. Hence, their mechanism may not trigger a rise in atmospheric $\mathrm{O}_{2}$.

There are three problems to consider. First, Gaillard et al. ${ }^{1}$ argue that the release of $\mathrm{SO}_{2}$ comes at the expense of $\mathrm{H}_{2} \mathrm{~S}$, according to:

$$
\mathrm{H}_{2} \mathrm{~S}+2 \mathrm{H}_{2} \mathrm{O} \rightarrow \mathrm{SO}_{2}+3 \mathrm{H}_{2}
$$

But the extra $\mathrm{H}_{2}$ released by this reaction exactly compensates for the switch from $\mathrm{H}_{2} \mathrm{~S}$ to $\mathrm{SO}_{2}$. The mixture of $\mathrm{SO}_{2}$ and $\mathrm{H}_{2}$ has the same redox potential as $\mathrm{H}_{2} \mathrm{~S}$ and water ${ }^{2}$. Fortunately, what happens in their model is different. The $\mathrm{H}_{2} \mathrm{~S}$ to $\mathrm{SO}_{2}$ ratio is buffered by magma, which has a fixed oxidation state, described in terms of a fixed oxygen fugacity. The relevant reaction is:

$$
\mathrm{H}_{2} \mathrm{~S}+{ }^{\prime} \mathrm{O}_{2}{ }^{\prime} \rightarrow \mathrm{SO}_{2}+\mathrm{H}_{2}
$$

where ' $\mathrm{O}_{2}$ ' represents oxidants (mostly ferric iron) in the melt. Reaction (2) produces $\mathrm{SO}_{2}$ and $\mathrm{H}_{2}$ in equimolar proportions, in agreement with results shown in figure 2 of ref. 1 . When $\mathrm{SO}_{2}$ is reduced to pyrite, $\mathrm{FeS}_{2}$, it consumes hydrogen as follows:

$$
4 \mathrm{SO}_{2}+10 \mathrm{H}_{2}+2 \mathrm{FeO} \rightarrow 2 \mathrm{FeS}_{2}+10 \mathrm{H}_{2} \mathrm{O}
$$

Because reaction (3) consumes more hydrogen per mole of $\mathrm{SO}_{2}$ than is produced by reaction (2), the net effect is to oxidize the atmosphere. Thus, this part of their proposed atmospheric oxidation mechanism appears to work, but not for the reasons they stated.

The second issue is that sulphur-containing gas fluxes are not the only ones that control $\mathrm{O}_{2} \cdot \mathrm{CO}_{2}$ is crucial because some $\mathrm{CO}_{2}$ is reduced to organic carbon, $\mathrm{CH}_{2} \mathrm{O}$, which is then buried. A mole of photosynthetic $\mathrm{O}_{2}$ is released for every mole of buried $\mathrm{CH}_{2} \mathrm{O}$. However, $\mathrm{O}_{2}$ can be lost in atmospheric reaction with $\mathrm{H}_{2}$, so the net effect is:

$$
\mathrm{CO}_{2}+2 \mathrm{H}_{2} \rightarrow \mathrm{CH}_{2} \mathrm{O}+\mathrm{H}_{2} \mathrm{O}
$$

The carbon isotope record suggests that $\sim 20 \%$ of outgassed $\mathrm{CO}_{2}$ is reduced and buried in this manner ${ }^{3,4}$. Holland ${ }^{4}$ quantified the effect of volcanic gases on the hydrogen budget by defining a parameter denoted $f$. Gases for which $f>1$ can reduce $20 \%$ of the $\mathrm{CO}_{2}$ to organic matter and all of the $\mathrm{SO}_{2}$ to pyrite, leaving excess hydrogen to support an anoxic atmosphere; gases with $f<1$ contain too little hydrogen to do this. Atmospheric $\mathrm{O}_{2}$ 'wins' over hydrogen when $f$ drops below unity. This analysis neglects other sources of hydrogen that might have been important (for example, serpentinization of ultramafic rocks on the continents and seafloor, or precipitation of ferric iron in banded iron formations), but it is useful for analysing the volcanic gases of ref. 1 .

In the model of Gaillard et al. ${ }^{1}$, the proportion of $\mathrm{CO}_{2}$ in released volcanic gases decreases by a factor of $\sim 3$ when volcanoes switch

Table $1 \mid f$ values for different cases from ref. 1

\begin{tabular}{ccc}
\hline \multirow{2}{*}{ Case } & \multicolumn{2}{c}{ Pressure (bar) } \\
\cline { 2 - 3 } & 1 & 100 \\
\hline Supplementary Table 1 & 0.60 & 0.62 \\
Supplementary Table 2 & 0.73 & 0.88 \\
\hline
\end{tabular}

from submarine to subaerial conditions because the pressure decreases from 100 bar to 1 bar. This change should tend to oppose atmospheric oxygenation, as less organic matter is buried (given a constant burial fraction), and thus less $\mathrm{H}_{2}$ is consumed. To estimate the net effect on atmospheric redox balance, we calculated $f$ values for cases listed in the Supplementary Information of ref. 1. Gaillard et al. ${ }^{1}$ include $\mathrm{S}_{2}$ as a species, which requires us to modify Holland's $f$ parameter, as follows:

$$
f=\frac{m\left(\mathrm{H}_{2}\right)+0.6 m(\mathrm{CO})-0.4 m\left(\mathrm{CO}_{2}\right)+3 m\left(\mathrm{H}_{2} \mathrm{~S}\right)+4 m\left(\mathrm{~S}_{2}\right)}{3.5\left[m\left(\mathrm{SO}_{2}\right)+m\left(\mathrm{H}_{2} \mathrm{~S}\right)+2 m\left(\mathrm{~S}_{2}\right)\right]}+\frac{1}{3.5}
$$

Here, $m(i)$ is the mole fraction of species $i$ in the released gases. As shown in Table 1, $f$ is less than unity in the cases shown in Supplementary Tables 1 and 2 of Gaillard et al. ${ }^{1}$, and so would not allow a reduced atmosphere before $2.4 \mathrm{Gyr}$ ago. This means that no rise of $\mathrm{O}_{2}$ is possible because the initial atmosphere is already oxidized. This could be because other hydrogen sources are neglected, as mentioned above, or because model parameters-for example, the outgassing temperature-are incorrect. In any case, the model, as presented in ref. 1, appears incapable of triggering a rise in atmospheric oxygen if Holland's method of analysis is correct.

Last, Gaillard et al. ${ }^{1}$ assume that gases released from a submarine magma at $1,300^{\circ} \mathrm{C}$ do not re-equilibrate with the surrounding basalts at lower temperatures as they emerge from depth; this assumption is at odds with previous work ${ }^{5,6}$. Such re-equilibration might have allowed Archaean volcanic gases to be more reduced; hence, a switch to subaerial volcanism around 2.5 Gyr ago might then result in atmospheric oxidation. But this would be a different oxidation mechanism from the one described in ref. 1 . There is also a broader caveat. The reduced oxidation state of volcanic gases comes at the expense of oxidizing the source rocks; thus, erosion and subsequent reduction of the source rocks may cancel out surficial redox change in the long term.

\section{James F. Kasting ${ }^{1}$, David C. Catling ${ }^{2}$ \& Kevin Zahnle ${ }^{3}$}

${ }^{1}$ Department of Geosciences, The Pennsylvania State University, 443 Deike, University Park, Pennsylvania 16802, USA.

email: kasting@essc.psu.edu

${ }^{2}$ Department of Earth and Space Sciences, and Astrobiology Program, Box 351310, University of Washington, Seattle, Washington 98195, USA. ${ }^{3}$ NASA Ames Research Center, MS 245-3, Moffett Field, California 94035, USA.

\section{Received 15 November 2011; accepted 17 May 2012.}

1. Gaillard, F., Scaillet, B. \& Arndt, N. T. Atmospheric oxygenation caused by a change in volcanic degassing pressure. Nature 478, 229-232 (2011).

2. Kasting, J. F. \& Brown, L. L. in The Molecular Origins of Life: Assembling the Pieces of the Puzzle (ed. Brack, A.) 35-56 (Cambridge Univ. Press, 1998).

3. Hayes, J. M. \& Waldbauer, J. R. The carbon cycle and associated redox processes through time, Phil. Trans. R. Soc. Lond. B 361, 931-950 (2006).

4. Holland, H. D. Volcanic gases, black smokers, and the Great Oxidation Event Geochim. Cosmochim. Acta 66, 3811-3826 (2002).

5. Kump, L. R. \& Seyfried, W. E. Hydrothermal Fe fluxes during the Precambrian: effect of low oceanic sulfate concentrations and low hydrostatic pressure on the composition of black smokers. Earth Planet. Sci. Lett. 235, 654-662 (2005).

6. Kump, L. R. \& Barley, M. E. Increased subaerial volcanism and the rise of atmospheric oxygen 2.5 billion years ago. Nature 448, 1033-1036 (2007).

Author Contributions All three authors contributed equally to this Comment.

Competing Financial Interests Declared none.

doi:10.1038/nature11274 


\section{Gaillard et al. reply}

REPLYING To J. F. Kasting, D. C. Catling \& K. Zahnle Nature 487, http://dx.doi.org/10.1038/nature11274 (2012)

Kasting et al. ${ }^{1}$ question the model of ref. 2 , in which we suggest that the oxygenation of the atmosphere, around $2.45 \mathrm{Gyr}$ ago, was promoted by the emergence of subaerial volcanism, producing volcanic gases with much more elevated $\mathrm{SO}_{2} / \mathrm{H}_{2} \mathrm{~S}$ ratios than submarine volcanism.

Kasting et al. ${ }^{1}$ claim that the enhanced $\mathrm{SO}_{2} / \mathrm{H}_{2} \mathrm{~S}$ ratio in subaerial volcanic gases was accompanied by enhanced $\mathrm{H}_{2}$ production, which may limit the oxidative capacity of emitted gases. This is only partly correct, because enhanced $\mathrm{SO}_{2}$ also derives from the reaction ${ }^{2,3}$ :

$$
\mathrm{S}^{2-} \text { (melt) }+3 \mathrm{Fe}_{2} \mathrm{O}_{3} \text { (melt) } \rightarrow \mathrm{SO}_{2}+6 \mathrm{FeO} \text { (melt) }+\mathrm{O}^{2-} \text { (melt) }
$$

which implies that subaerial degassing extracts more oxygen from the melt than submarine degassing. The oxygen reservoir of the melt, a fundamental aspect of our model ${ }^{3}$ that has so far not been taken into account, implies that more oxygen was therefore degassed as subaerial volcanism became abundant at about 2.7 Gyr ago.

Also, Kasting et al. ${ }^{1}$ argue that the amount of outgassed $\mathrm{CO}_{2}$ decreases by a factor of 3 as venting pressure decreases from $100 \mathrm{bar}$ to 1 bar, which should limit production of organic carbon $\left(\mathrm{CH}_{2} \mathrm{O}\right)$ and thereby limit the associated consumption ${ }^{4}$ of atmospheric $\mathrm{H}_{2}$. However, although the molar fraction of $\mathrm{CO}_{2}$ in the gas decreases, the flux of $\mathrm{CO}_{2}$ into the atmosphere is unchanged between 100 and 1 bar venting pressures ${ }^{2}$, owing to the exceedingly low solubility of $\mathrm{CO}_{2}$ in silicate melt in this pressure range (unlike the case for sulphur).

The $f$ parameter of Holland ${ }^{4}$ is used by Kasting et al. ${ }^{1}$ to evaluate how much $\mathrm{H}_{2}$ is consumed to reduce volcanic $\mathrm{CO}_{2}$ into organic matter and $\mathrm{SO}_{2}$ to pyrite. According to Kasting et al. ${ }^{1}$, as pressure decreases, the $f$ values of our calculated gas compositions indeed decrease (that is, their reducing power decreases, as required), but do not reach low enough values to drive the atmosphere to oxidizing conditions. However, the calculation of $f$ is based on the way $\mathrm{H}_{2} \mathrm{~S}$ is produced or consumed in volcanic gases: Holland ${ }^{4}$ first considered decomposition of $\mathrm{H}_{2} \mathrm{~S}$ during cooling, which is equivalent to production of $\mathrm{H}_{2}$ (hence the $+3 m\left(\mathrm{H}_{2} \mathrm{~S}\right)$ term in the $f$ equation). The more recent analysis ${ }^{5}$ by Holland considers instead that $\mathrm{H}_{2} \mathrm{~S}$ is the product of reaction between $\mathrm{SO}_{2}$ and $\mathrm{H}_{2}$ during cooling, a $\mathrm{H}_{2}$-consuming reaction $\left(-3 m\left(\mathrm{H}_{2} \mathrm{~S}\right)\right.$ in the $f$ equation).

Conventionally, about $20 \%$ of volcanic $\mathrm{CO}_{2}$ is consumed to produce organic matter ${ }^{4}$. Any variation of the amount severely affects the results of calculations made using the $f$ equation, highlighting the difficulties in using it as to determine the oxidative capacity of volcanic gases. Holland's more recent analysis ${ }^{5}$ of the causes of oxygenation suggests that oxidation was due to an increase in $\mathrm{CO}_{2}$ and $\mathrm{SO}_{2}$ volcanic fluxes, which is what our model predicts as volcanism changed from quasi-exclusively-submarine to partially subaerial. At this point, we stress that our model ${ }^{2}$ not only describes an increase in the oxidative capacity of volcanic gas but also a chain reaction likely to facilitate atmospheric oxygenation. Of prime importance are the sulphate reduction processes, which should have been exacerbated by elevated volcanic $\mathrm{SO}_{2}$ emissions. Biological sulphate reduction transforms sedimentary organic carbon into $\mathrm{CO}_{2}$, which results in oxygen production ${ }^{6}$. In parallel, hydrothermal sulphate reduction, which decreases the reducing potential of hydrothermal fluids and fixes hydrothermal ferrous iron as pyrite, also contributed to atmospheric oxygenation ${ }^{4}$. All these reaction paths are not included in Holland's $f$ factor, whereas they were certainly involved in the Great Oxidation Event.

We agree with the final recommendation of Kasting et al. ${ }^{1}$ that both volcanic gases and hydrothermal fluids should be considered in models of the Great Oxidation Event. However, whereas we accept that thick Archaean oceanic crust was on average more mafic than younger crust, the uppermost layers-those most susceptible to hydrothermal alteration-would have consisted of olivine-poor basalt. In both modern oceanic plateaus and presumably in Archaean oceanic crust, parental picritic magma differentiates, leaving olivine cumulates at the Moho and erupting relatively evolved lava ${ }^{7}$. Basalt with little to no olivine is the dominant component of the upper parts of both modern oceanic plateaus and Archaean greenstone belts ${ }^{7,8}$. These rocks are not susceptible to serpentinization; therefore little $\mathrm{H}_{2}$ would have been produced during their hydrothermal alteration, and its impact on the atmospheric oxygenation should not have been as important as claimed by Kasting et al. ${ }^{1}$.

Last, Kasting et al. ${ }^{1}$ expressed concern about low-temperature re-equilibration processes between volcanic gases and basalts that were not considered by $\mathrm{us}^{2}$. We answer that this comment seems to re-introduce confusion between volcanic gas inputs (from mantle to exosphere) and hydrothermal recycling (seawater that reacts with basalts) that may arise from a misinterpretation of ref. 9. Volcanic degassing and hydrothermal emissions are two fundamentally distinct processes, which not only differ in temperature, but chiefly differ in their source (igneous input versus surficial recyling).

\section{Fabrice Gaillard ${ }^{1}$, Bruno Scaillet ${ }^{1}$ \& Nicholas T. Arndt ${ }^{2}$}

${ }^{1}$ Institut des Sciences de la Terre d'Orléans, CNRS-INSU/Université d'Orléans/Université de Tours, 1 a rue de la Férollerie 45071, Orléans cedex 2, France.

${ }^{2}$ ISTerre, Université Joseph Fourier de Grenoble, CNRS, 1381 rue de la Piscine, 38400 Saint Martin d'Hères, France.

email: fabrice.gaillard@cnrs-orleans.fr

1. Kasting, J. F. Catling, D. C. \& Zahnle, K. Atmospheric oxygenation and volcanism. Nature 487, http://dx.doi.org/10.1038/nature11274 (2012).

2. Gaillard, F., Scaillet, B.\& Arndt, N. T. Atmospheric oxygenation caused by a change in volcanic degassing pressure. Nature 478, 229-232 (2011).

3. Gaillard, F. \& Scaillet, B. The sulfur content of volcanic gases on Mars. Earth Planet. Sci. Lett. 279, 34-43 (2009).

4. Holland, H. D. Volcanic gases, black smokers, and the Great Oxidation Event. Geochim. Cosmochim. Acta 66, 3811-3826 (2002).

5. Holland, H. D. Why the atmosphere became oxygenated: a proposal. Geochim. Cosmochim. Acta 73, 5241-5255 (2009).

6. Lyons, T. W. \& Gill, B. C. Ancient sulfur cycling and oxygenation of the early biosphere. Elements 6, 93-99 (2010).

7. Fitton, J. G., Mahoney, J. J., Wallace, P. J. \& Saunders, A. D. (eds) Origin and Evolution of the Ontong Java Plateau (Geological Society of London, 2004).

8. de Wit, M. J. \& Ashwal, L. D. Greenstone Belts (Oxford Scientific, 1997).

9. Kump, L. R. \& Barley, M. E. Increased subaerial volcanism and the rise of atmospheric oxygen 2.5 billion years ago. Nature 448, 1033-1036 (2007).

doi:10.1038/nature1 1275 